\title{
Discussion on the Usability of Digital Mobile Museum Website: An Example of Pazeh Culture Mobile Museum Website
}

\author{
Hsiu Ching Laura $\mathrm{Hsieh}^{1 *}$, Yu Quan Chen ${ }^{2}$ \\ ${ }^{1,2}$ Department and Graduate School of Creative Design, National Yunlin University of Science and Technology \\ *Corresponding author. Email:inclusive85413@gamil.com
}

\begin{abstract}
To cope with the trend of global informatization, physical museums promote online digital mobile museums to establish the new model to interact with audience.The Pazeh, located in Liyutan village in Miaoli County, presents special Pazeh language, festival, and ecology. There is a physical Pazeh museum in the village, but the remote location results in Pazeh culture not being effectively promoted. Pazeh culture mobile museum website promotes Pazeh culture through digitalization and promotes the cultural identity of the Pazeh. Taking Pazeh culture mobile museum website as the research object, the major objectives include 1.to construct a digital mobile museum website and 2.to discuss the usability of the digital mobile museum website. System Usability Scale (SUS) is applied to understand the users' usability feedback about the digital mobile museum website. According to the research results, suggestions are proposed for the future design and development of Pazeh culture mobile museum website.
\end{abstract}

Keywords: Pazeh, digital mobile museum website, culture promotion

\section{INTRODUCTION}

\section{Background information}

The advancement in technology has greatly accelerated the rise of internet and thus the prevalence of websites which have become the main tool of searching and learning for the users. The Pazeh Tribe in Liyutan Village, Sanyi, Miaoli County has many unique culture and ecological resources, but the local museum has not effectively promoted Pazeh culture. Digital mobile museum website is the most economical way of promotion in which there is no boundary for the dissemination of information while achieving cultural promotion is also possible. The objective of the research is for the establishment of Pazeh Cultural Mobile Museum website, integrating the historical information and natural resources of the Pazeh Tribe. Through interactive web pages and recording Pazeh culture digitally, not only the participation of users would be increased but also the awareness for preserving Pazeh culture in the Pazeh people and the public would be stimulated.

\section{Research purpose}

This research has two purposes:

(1) Construct a digital mobile museum
(2) Discuss the usability of the digital mobile museum website.

\section{LITERATURE REVIEW}

The literature information of the research is : Digital mobile museum website, Usability and Interface design, Interactive web design, and Pazeh Culture, all of which will be explained one by one below.

\section{Digital mobile museum website}

With the rise of internet, physical museum is transforming toward digitalization. Visitors to museums in the past have been restricted by the duration of the exhibition and the space of the museum. Museums have only the initial function of exhibition without providing further exploration service to the people. Digitalization differentiates the museum website from the physical museum in that the website can present all relevant information of the exhibition in a digital fashion to the public (Pai-hsun Chen, Jieh Hsiang, Tsung-mo Chiang\& Jen-shin Hong,2000). Digital mobile museum solves the restrictions of the physical museum and becomes an extension of the physical museum through integrating resources by means of digital technology. website 


\section{Usability and Interface Design}

Usability is having in the center the users who can instinctively and efficiently use the product, interface, or system. In 1993, the scholar Nielsen defined usability as the function a user can easily use a system, and he also set the 5 standards of usability evaluation as easy to learn, easy to remember, usage efficacy, few operation errors, and user satisfaction. In 1994, the scholar Preece further defined usability as the degree of ease, effectiveness, efficiency, and security of the system used and the attitude of the users for operating the system. Interface is a medium that can facilitate communications between people or between people and the system (Aaron Marcus,2002). In order to have the interface be suitable for people so that communications between people and system, between people, testing the usability must be undertaken when constructing the interface. In 1999, Wu De Ming proposed the interface design process in which during the first phase, the need of the user is analyzed. In the second phase is the construction of interface model after which the interface can undergo usability testing by the users who take the test and errors can be corrected. The last phase is to repeatedly undergo revisions until all errors are corrected.

\section{Interactive Web Design}

Interactive web page is a user-oriented website that is logically different from the regular informationoriented web page. Interactive web pages transmits graphics, texts, and information to the users in multiple ways (Li,Xian Huei,1999). Interactive web page preference provides new experience to the users. Clicking on buttons and the mouse, animations and other ways topple the experience of operating the website by the users. More attention to the content of the website by the users will thus happen.

\section{Pazeh Culture}

Pazeh is one of the Pingpu Tribes in Taiwan and is distributed in Liyutan Village in Sanyi of Miaoli County, Dashe Village in Fengyuan District of Taichung City, and Ailan of Puli Township in Nantou County(Zhang-Su Fen,2007). The subject of the research are the Pazeh people in Liyutan Village in Sanyi of Miaoli County. After undergoing field investigation and exploring literatures, four categories of Symbols 、 Heroes 、 Rituals, and Values are classified according to the Cultural Onion Mode by Hofsted in 2010. The four categories are introduced in the following:

\section{4-1. Symbols}

The Pazeh in the Liyutan village have unique and diverse cultural characteristics, The following classifies the Pazeh symbol as five items:

(1). Attractions and Monument
The Liyutan village is surrounded by monuments and buildings such as Longteng Bridge and Liyutan Reservoir.

(2). Ecological resources

The Liyutan village is rich in natural resources. Such as Leopard Cat, Sus Scrofa Taiwanus, Muntiacus Reevesi, Ring-cupped Oak and Letterwood.

\section{(3). Hunting}

The Pazeh people fished in the Doroko River with hunting equipment such as Harpoon, Eel cage, Gobies cage, and Crab cage.

\section{(4).Clothing}

Including ritual clothing, social class symbol jewelry, daily clothing .The social class is distinguished by the complexity of textile technology. (Li,Zi Ning,Wu, Pai Lu,2016)

\section{(5). Food}

The Pazeh people live on fishing, so their diet consists mostly of fish processing such as Gobies, Fish rice cake, Mitten crab.

\section{4-2. Heroes}

In 1761, the Pazehs emigrated from Dashe to Liyutan Village. Due to the fertile land, after a few decades, the place attracted the Hakka and Minnan people. Liyutan Village became a 'melting pot' where the three peoples coexisted (Lin,Xiu Che,2007) and invisibly influenced the Pazehs with Chinese culture. In 2010, after the last elder lady, Ms. Pan Jin Yu, who is well versed in the Pazeh language, Pazeh was listed as a language at the verge of distinction. The Pazehs started a Pazeh culture renaissance where Pan Ing Qi, the director of Pazeh Tribe Association and his father, Pan Da Zhou teach the tribal language at the Liyutan church every week to pass on the language. They also built the Pazeh Museum with great effort to protect the Pazeh culture.

\section{4-3. Rituals}

Liyutan Elementary School is where the Pazeh new year's festivities and rituals are held annually after the establishment of Taiwan Pazeh Cultural Association in 1999 (Tian,Xuan Hao,2016), inviting all Pazehs to come celebrate together. Gong dance starts the festivities and playing the gongs signifies the beginning of the New Year. 'Zou Biao' is the marathon for men. The men who crossed the finish line would win a satin flag that represents manhood and courage and the respect of the whole village(Bazai Ethnic Association,2015). During the festivities, singing of the Aiyen song commemorates the ancestors and offer gratitude to the heaven(Li,Ren Gui, Lin,Ching Tsai,2002). At the conclusion of the festivity, people are invited to have Pazeh style meal and to dance around in the plaza.

\section{4-4. Values}

Since opening of port for commerce in 1860, Christianity spread to Ailanli and became the main religion of the Pazehs (Lin,Xiu Che,2007). The village also has the Hakka and Minnan peoples, the coexistence of Liyutan Church with the Earth God 
the understanding of Pazeh's rich culture and natural resources on line. The website will also compile all the rituals, sites, culture, and natural resources in the website so that the public will have a more comprehensive knowledge of the Pazeh Tribe without having to step into Liyutan Village and the goal of promoting Pazeh culture will be achieved.

\section{METHOD}

\section{Research Object}

The research is to explore the usability of the digital mobile museum website. There was a need to have the feedback of the testing users, so 15 heavy internet student users between ages 18 15 were chosen to undergo testing. astounding than visiting a museum. Through Pazeh Cultural Mobile Museum website, the public can gain

\section{Research Procedure}

There are six steps in this research, Please see the figure below.

\begin{tabular}{|c|c|c|c|c|c|}
\hline $\begin{array}{c}\text { Field } \\
\text { investigation } \\
\text { and data } \\
\text { collection }\end{array}$ & $\begin{array}{l}\text { Construction of } \\
\text { information } \\
\text { structure of Pazeh } \\
\text { Cultural Mobile } \\
\text { Museum website }\end{array}$ & $\begin{array}{l}\text { Transform the } \\
\text { information } \\
\text { structure into an } \\
\text { interface } \\
\text { prototype }\end{array}$ & $\begin{array}{l}\text { Recruit } \\
\text { users for } \\
\text { testing }\end{array}$ & $\begin{array}{c}\text { Apply the system usability } \\
\text { scale (SUS) and open } \\
\text { questionnaire to evaluate } \\
\text { usability }\end{array}$ & $\begin{array}{l}\text { Statistics } \\
\text { and } \\
\text { Analysis the } \\
\text { system } \\
\text { usability } \\
\text { scale (SUS) }\end{array}$ \\
\hline
\end{tabular}

Figure 1. Research procedure

\section{2-1. Field investigation and data collection}

Pazeh data was procured through going to Liyutan Village to undertake field investigation, text and photograph recording, perusing historical information, participation in local activities to experience local culture, and interview with the villagers. In addition, the initial the Pazeh Cultural Mobile Museum website was established. Further exchange and discussion with the villagers and revision of information mistakes were carried out before finishing the final version of the information structure of Pazeh Cultural Mobile Museum website.

\section{2-2. Cnstruction of information structure of}

Pazeh Cultural Mobile Museum website

The information structure of Pazeh Cultural Mobile Museum website have four extensions, Symbols, Heroes, Rituals, and Values.

\section{Pazeh culture mobile museum website}

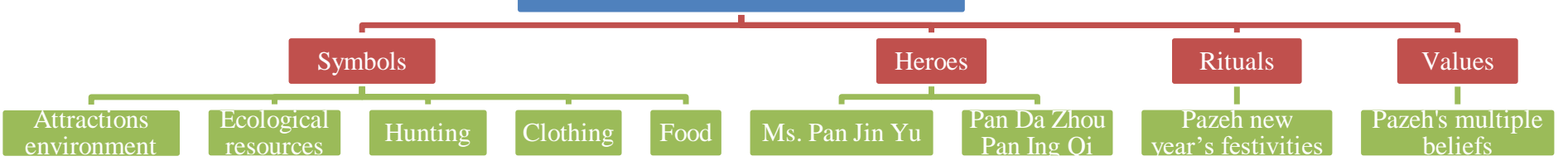

Figure 2. Information structure of Pazeh Cultural Mobile Museum website

\section{2-3. Transform the information structure into an interface prototype}

Integrate the graphics from field investigation and data collection and transform to illustrations and animations to increase the interactivity of the website. 


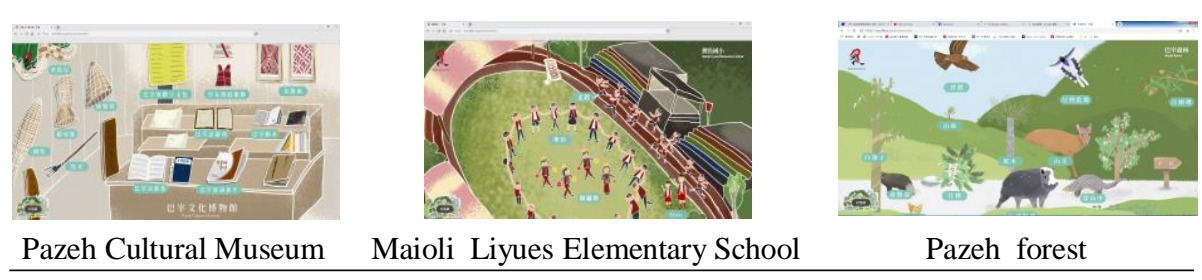

\section{2-4.Recruit users for testing}

The subjects were 15 students between the ages of 18 and 25 who filled out questionnaire after using. Each subject was numbered as $\mathrm{S} 1, \mathrm{~S} 2$, and so on.

Table 2. questionnaire respondents

$\begin{array}{ll}\text { Subject } & \text { numbered } \\ \text { Student } & \text { S(S1,S2 ... and so on })\end{array}$

\section{2-5. Apply the system usability scale (SUS) and open questionnaire to evaluate usability}

The questionnaire was executed based on the SUS devised by John Brooke on 15 users. In addition, through the questions, the level of understanding the website and the recommendations by the testing users will be derived. The SUS is a standardized questionnaire devised by John Brook to be used on testing system interface, website interface, interface prototype. Improvement of the interface can be implemented based on the testing result. The questionnaire is divided into two phases. The first phase is the SUS with a total of 10 questions using Likert Scale. The questions are as follows: frequently.

1. I think that I would like to use this website

2. I found the website unnecessarily complex.

3 . I thought the website was easy to use.

4. I think that I would need the support of a technical person to be able to use this website.

5. I found the various functions in this website were well integrated.

6. I thought there was too much inconsistency in this website.

7. I would imagine that most people would learn to use this website very quickly.

8. I found the website very cumbersome to use.

9. I felt very confident using the website.
10. I needed to learn a lot of things before I could get going with this website.

The second phase is open-ended questions for the objective of the degree of understanding the website after the testing users have operated the website and the feedback on the website. There are a total of 8 questions as in the following: New Year.

1. Please indicate the four rituals of Pazen's

2. Please indicate the two Artiodactyla animals in the Pazeh forest.

3. Please indicate the way the Pazeh clansman hunt in their daily lives.

4. Please indicate the most important river in the village of Pazeh.

6. Please indicate the parts you don't like when using this website.

7. Please indicate the parts that are not going well when using this website.

8. Please indicate the part of this website that is not disagree for use.

\section{2-6. Statistics and Analysis the system} usability scale (SUS)

The first phase questionnaire results, Please see the table below.

Table 3. The first phase questionnaire results

\begin{tabular}{ccccccccccccc} 
Subject/Question & Q1 & Q2 & Q3 & Q4 & Q5 & Q6 & Q7 & Q8 & Q9 & Q10 & SUS Scores & SUS GradeScale \\
\hline S1 & 4 & 2 & 5 & 1 & 5 & 1 & 5 & 1 & 5 & 1 & 95 & A \\
S2 & 3 & 2 & 5 & 1 & 4 & 1 & 5 & 2 & 5 & 2 & 85 & B \\
S3 & 3 & 2 & 4 & 1 & 3 & 3 & 5 & 2 & 5 & 2 & 75 & C \\
S4 & 3 & 2 & 5 & 1 & 4 & 2 & 5 & 1 & 5 & 1 & 87.5 & B \\
S5 & 5 & 2 & 4 & 2 & 4 & 2 & 5 & 1 & 4 & 2 & 82.5 & B \\
S6 & 3 & 2 & 5 & 1 & 4 & 2 & 5 & 2 & 5 & 1 & 85 & B
\end{tabular}




\begin{tabular}{ccccccccccccc} 
S7 & 4 & 1 & 5 & 2 & 5 & 1 & 5 & 1 & 5 & 1 & 95 & A \\
S8 & 3 & 1 & 5 & 1 & 5 & 2 & 5 & 1 & 5 & 1 & 92.5 & A \\
S9 & 3 & 1 & 5 & 1 & 3 & 2 & 5 & 1 & 5 & 1 & 87.5 & B \\
S10 & 3 & 1 & 4 & 1 & 3 & 3 & 5 & 1 & 5 & 1 & 82.5 & B \\
S11 & 2 & 1 & 4 & 1 & 3 & 2 & 5 & 1 & 4 & 2 & 77.5 & C \\
S12 & 2 & 1 & 5 & 2 & 5 & 2 & 5 & 1 & 4 & 1 & 85 & B \\
S13 & 3 & 1 & 5 & 1 & 4 & 2 & 5 & 2 & 5 & 2 & 85 & B \\
S14 & 4 & 2 & 4 & 1 & 4 & 2 & 4 & 2 & 5 & 2 & 80 & B \\
S15 & 2 & 1 & 4 & 1 & 4 & 2 & 5 & 1 & 4 & 1 & 82.5 & B \\
\hline
\end{tabular}

In the second phase of the questionnaire, questions number one to number four have standard answers. 1 means the user answered correctly, 2 means answered incorrectly.Please see the table below.

Table 4. The Second phase questionnaire results

\begin{tabular}{ccccc} 
Subject/Question & Q1 & Q2 & Q3 & Q4 \\
\hline S1 & 1 & 1 & 1 & 1 \\
S2 & 1 & 1 & 2 & 1 \\
S3 & 1 & 1 & 1 & 1 \\
S4 & 1 & 1 & 1 & 1 \\
S5 & 1 & 1 & 1 & 1 \\
& 1 & 1 & 1 & 1 \\
S6 & 1 & 1 & 1 & 1 \\
S7 & 1 & 1 & 1 & 1 \\
S8 & 1 & 2 & 1 & 1 \\
S9 & 1 & 1 & 1 & 1 \\
S10 & 1 & 1 & 1 & 1 \\
S11 & 1 & 2 & 1 & 1 \\
S12 & 1 & 1 & 1 & 1 \\
S13 & 1 & 1 & 1 & 1 \\
S14 & 1 & 2 & 1 & 1 \\
S15 & & & &
\end{tabular}

\section{RESULTS}

The research explored the usability of the Pazeh Cultural Mobile Museum by deploying the system usability scale (SUS).The average score of SUS is 70 (Bangor, A., Kortum, P. T., \& Miller, J. $\mathrm{T} ., 2008)$. The average score of the website is 85.16 , above the average. SUS has five levels (Bangor, A., Kortum, P. T., \& Miller, J. T.,2008). Of the 15 users who underwent the testing, 3 gave an A rating, 10 B's, and 2 C's; all 15 are within acceptable range, meaning that the usability of the Pazeh Cultural Mobile Museum website has reached average goal. In the first 4 questions of the open answer part, the questions ranged from the ecology of the Pazeh Tribe, culture, fishing and rituals. The goal of the questions was to test the degree of understanding the website by the testing users. Out of the 15 testing users, 11 answered all correctly, and the rest of the 4 missed one question, meaning that the Pazeh Cultural Mobile Museum is easy to understand and is able to provide knowledge to users.

The latter 4 questions of the open answer part are the feedback from the testing users. In the survey, the testing users liked having illustrations as a format for an interactive website to attract the users. The following interviews with subjects S2, S9, and S15 are such proof.

I liked the style of the design. The animation is vivid and more fun and livelier than the average knowledge-oriented websites. (S2-5Q)

The illustrations are exquisite much more vivacious than other boring web pages. (S8-5Q)

I liked the style presented by the illustrations. The color tones make people feel warm. The introductions of the surrounding environment is diverse. Want to get to learn more about Pazeh. (S155Q)

In terms of website operation, the testers think that the operating the Pazeh Cultural Mobile Museum website is intuitive and helpful in understanding the Pazeh culture. The following interviews with subjects S7, S11, and S14 are such proof:

The interface is simple and clear. It is very good to have diverse and comprehensive cultural knowledge. (S7-5Q) 
The website is simple and direct. I can understand the local geographic and related information by just looking at the map. The interactive website is fun, very attractive making people want to understand more about Pazeh. (S115Q)

Operation is simple and understandable. The tribal icons are distinctive. Visual feedback is refined. Understanding Pazeh culture is even swifter. (S14-5Q)

Operating the website is intuitive and learning interest is elevated. (S10-5Q)

\section{DISCUSSION}

According to the testing results, the acceptance rate in terms of the illustrations and interactive structure of the Pazeh Cultural Mobile Museum website is quite high among the users who also prefer easy intuitive operation. Interactive website can better attract users to browse the web pages more closely, and the users can gain more information on the Pazeh culture. Intuitive clicking also increases the operation efficiency of the website and reduces mistakes thus enhancing the acceptance rate by the users.

The Pazeh Cultural Mobile Museum website is different from other mobile museums in that it changes the impression in the public of the information-oriented digital mobile museums and is more able to attract users to visit the Pazeh Cultural Mobile Museum website plus achieving the goal of inspiring the public awareness on preserving Pazeh culture. The research explored the usability of the Pazeh Cultural Mobile Museum. During the process of creation, some sticking points were discovered. The recommendations from the testing users are provided for future development of the Pazeh Cultural Mobile Museum website as reference.

\section{REFERENCES}

[1] Bazai Ethnic Association(2015).Pazeh new year.Miaoli: Bazai Ethnic Association.

[2] Hofstede, G., Hofstede, G.J., Minkov, M. (2010)Cultures and Organizations - Software of the Mind. Maidenhead : McGraw-Hill.

[3] Lin,Xiu Che(2003). Distribution and Population of PingPu.Taipei: Council of Indigenous Peoples, Executive Yuan.
[4] Lin,Xiu Che(2007). The Pazeh ethnography survey.Taipei: Council of Indigenous Peoples, Executive Yuan.

[5] Li,Ren Gui,Lin,Chin Tasi(2002).Pazih texts and songs.Taipei:Institute of Linguistics, Academia sinica.

[6] Nielsen, J. (1993).Usability Engineering, San Francisco, USA : Morgan Kaufmann Publishers Inc.

[7] Preece, J.,Rogers, Y.,Sharp, H.,Benyon, D.,Holland,S.,Carey, T.(1994). Human computer interaction. Essex, UK :AddisonWesley Longman Ltd.

[8] Pan-Da Ho(2002). The History of Pingpu Pazeh: A Hero in the History of Taiwan's Development.Taipei: MC Publishing Inc.

[9] Zhang-Su Fen(2007).Miaoli Liyutan Pazeh history paleography compilation. Miaoli : Culture and Tourism Bureau, Miaoli County.

[10] Aaron Marcus (2002). Dare we define userinterface design?.Association for Computing Machinery, 9(5), 19-24.

[11] Bangor, A., Kortum, P. T., \& Miller, J. T. (2008). An empirical evaluation of the System Usability Scale. International Journal of Human-Computer Interaction, 24(6), 574594.

[12] Pai-hsun Chen, Jieh Hsiang, Tsung-mo Chiang\& Jen-shin Hong (2002). Discussion of Digital Museums,Museology Quarterly,16(3), 15-37.

[13] Li-Zi Ning,Wu-Pai Lu(2016).Digitizing Project on the Formosa Aborigines Collection of National Taiwan Museum (VIII) (Research Grant NSC100-2631-H115-001 ).Taipei: National Science Council, Executive Yuan.

[14] Tian,Xuan Hao(2016).The ethnic certification movement of Pazeh, National Chengchi University Ethnology Department thesis, Taipei .

[15] Type and characteristics of the website(1999).Li,Xian Huei.Retrieved from http://vr.theatre.ntu.edu.tw/hlee/course/th7_5 30/th7_530d3.htm (Aug. 6, 2019) 